\title{
STUDI ETNOBOTANI TUMBUHAN OBAT BERBASIS PENGETAHUAN LOKAL \\ DI DESA SELOLIMAN KECAMATAN TRAWAS KABUPATEN MOJOKERTO JAWA TIMUR
}

\author{
Iif Hanifa Nurrosyidah ${ }^{1}$, Milu Asri Riya ${ }^{2}$, Alfian Fachruddin Ma'ruf ${ }^{3}$ \\ ${ }^{1,2,3}$ STIKES Rumah Sakit Anwar Medika
}

Email korespondensi: iifnurrosyidah@yahoo.co.id

\begin{abstract}
ABSTRAK
Indonesia adalah negara dengan keanekaragaman hayati terbesar kedua setelah Brazil, dimana 20.000 jenis tumbuhan obat dimana 1.000 jenis tumbuhan telah didokumentasi dan 300 jenis telah dimanfaatkan sebagai obat tradisional. Seloliman adalah sebuah desa yang beradaa di lereng gunung Penanggungan Kecamatan Trawas Kabupaten Mojokerto Jawa Timur. Masyarakat desa Seloliman hidupnya masih bergantung dari alam, sebagian besar masyarakat masih memanfaatkan bahan alam untuk pengobatan dan kebutuhan sehari hari. Oleh karena itu pada penelitian ini akan dilakukan studi etnobotani dan dan identifikasi tumbuhan obat berbasis pengetahuan lokal di Desa Seloliman Kecamatan Trawas Kabupaten Mojokerto Jawa Timur. Penelitian dilakukan dengan menggali potensi masyarakat sebagai tempat penelitian etnobotani dengan metode observasi dan wawancara terbuka. Teknik pemilihan informan berdasarkan informasi penduduk setempat atau kepala desa yang dinggap paling mengetahui tentang tumbuhan obat. Mengumpulkan data tumbuhan obat yang digunakan untuk pengobatan tradisional melalui wawancara terstruktur. Data yang dicatat adalah nama lokal, nama latin, nama famili, cara memperoleh, bagian tanaman yang digunakan, penyakit yang diobati, dan cara penggunaannya. Selanjutnya setiap jenis tumbuhan yang digunakan didokumentasikan. Berdasarkan hasil penelitian yang dilakukan adalah jenis tanaman yang digunakan untuk pengobatan sangat bervariasi, bagian tanaman yang digunakan sebagian besar adalah bagian daun (57\%), bunga (10\%), dan sisanya adalah bagian batang, kulit batang, rimpang, akar, bunga, buah, dan biji. Sumber tanaman yang digunakan sebagian besar adalah tanaman budidaya (46\%), liar (30\%), liar dan budidaya (17\%) dan membeli di pasar (7\%). Sedangkan cara penggunaannya sebagian besar dengan direbus. Masyarakat desa Seloliman Kecamatan Trawas Kabupaten Mojokerto Jawa Timur sebagian besar sudah terpengaruh oleh budaya luar, sehingga pengetahuan lokalnya mengenai tumbuhan yang digunakan dalam pengobatan perlu digali lebih jauh agar dapat dilestarikan. Hanya terdapat terdapat dua narasumber (pengobat tradisional) di desa Seloliman yang masih memegang tradisi terkait pengobatan dengan menggunakan bahan alam.
\end{abstract}

Kata kunci: Etnobotani, Seloliman, Trawas, Mojokerto 


\title{
ETHNOBOTANIC STUDY OF LOCAL KNOWLEDGE-BASED MEDICINE PLANT \\ IN SELOLIMAN VILLAGE, KECAMATAN TRAWAS, MOJOKERTO DISTRICT EAST JAVA
}

\begin{abstract}
Indonesia is the country with the second largest biodiversity after Brazil, where 20,000 species of medicinal plants in which 1,000 species have been documented and 300 species have been used as traditional medicine. Seloliman is a village located on the slopes of Mount Penanggungan, Trawas District, Mojokerto Regency, East Java. The people of Seloliman village still depend on nature, most people still use natural materials for treatment and daily needs. Therefore in this research ethnobotany study and identification of medicinal plants based on local knowledge will be conducted in Seloliman Village, Trawas District, Mojokerto Regency, East Java. The study was conducted by exploring the potential of the community as a place of ethnobotany research with open observation and interview methods. The technique for selecting informants is based on information from local residents or village heads who are most aware of medicinal plants. Collecting data on medicinal plants used for traditional medicine through structured interviews. Data recorded are local names, Latin names, family names, ways of obtaining, parts of plants used, diseases treated, and how they are used. Furthermore, each type of plant used is documented. Based on the results of research conducted is the type of plant used for treatment varies greatly, the plant parts used are mostly the leaves (57\%), flowers (10\%), and the rest are the stem, bark, rhizome, roots, flowers, fruit and seeds. Sources of plants used are mostly cultivated plants (46\%), wild (30\%), wild and cultivated (17\%) and bought on the market (7\%). While the way to use it is mostly boiled. Most of the Seloliman village community, Trawas Subdistrict, Mojokerto Regency, East Java have been influenced by outside cultures, so that their local knowledge about plants used in medicine needs to be further explored in order to be preserved. There are only two speakers (traditional healers) in the village of Seloliman who still hold the tradition related to treatment using natural materials.
\end{abstract}

Keywords: Ethnobotany, Seloliman, Trawas, Mojokerto

\section{PENDAHULUAN}

Sejak zaman dahulu, manusia sangat mengandalkan lingkungan sekitarnya untuk memenuhi kebutuhannya. Misalnya untuk makan, tempat berteduh, pakaian, obat, pupuk, parfum, dan bahkan untuk kecantikan dapat diperoleh dari lingkungan. Sehingga kekayaan alam di sekitar manusia sebenarnya sedemikian rupa sangat bermanfaat dan belum sepenuhnya digali, dimanfaatkan atau bahkan dikembangkan. Indonesia memiliki budaya pengobatan tradisional dalam penggunaan tumbuhan obat sejak dulu dan dilestarikan secara turun-temurun (Islami et al., 2017). 
Indonesia menyimpan potensi tumbuhan obat sebanyak 30.000 jenis, di antaranya 940 jenis telah dinyatakan berkhasiat obat, $78 \%$ masih diperoleh melalui pengambilan langsung dari hutan (Nugroho, 2010). Pengetahuan mengenai tumbuhan obat memiliki karakteristik berbeda-beda pada suatu wilayah. Banyaknya jenis tumbuhan yang digunakan sebagai obat tradisional dapat memberikan referensi terhadap dunia pengobatan, apalagi dengan makin gencarnya moto "back to nature" atau "kembali ke alam". Pengobatan tradisional awalnya dikenal dengan ramuan jamujamuan, sampai saat ini jamu masih diyakini sebagai obat mujarab untuk mengobati berbagai penyakit bahkan telah dikembangkan dalam industri modern (Dianto et al., 2015). Pengetahuan mengenai tumbuhan obat memiliki karakteristik berbeda-beda pada suatu wilayah. Pengetahuan tersebut biasanya merupakan warisan secara turun-menurun (Nurrani, 2013).

Akhir-akhir ini penelitian tentang pengetahuan dan pemanfaatan tumbuhan obat oleh masyarakat lokal telah banyak dilakukan,.Penelitian mengenai Pemanfaatan Tumbuhan Obat Oleh Masyarakat Di Desa Entogong Kecamatan Kayan Hulu Kabupaten Sintang oleh Diba \& Tavita (2017), penelitian Husain (2015) tentang Studi Etnobotani dan Identifikasi Tumbuhan Obat Berbasis Pengetahuan Lokal di Kabupaten Enrekang, penelitian Nursiyah (2013) tentang Studi Deskriptif Tanaman Obat Tradisional yang digunakan Orang Tua Untuk Kesehatan Anak Usia Dini di Gugus Melati Kecamatan Kalikanjar Kabupaten Wonosobo, penelitian Balai Besar Penelitian Dipterokarpa et al. (2011) tentang Keanekaragaman Jenis Tumbuhan Obat dan Pemanfaatannya di Kawasan Tane' Olen Desa Setulang Malinau Kalimantan Timur serta masih banyak penelitian lainnya.

Seloliman adalah sebuah desa yang indah dan hijau yang beradaa di lereng gunung Penanggungan (TrawasMojokerto). Masyarakat desa Seloliman hidupnya masih bergantung dari alam, salah satunya adalah matapencaharian sebagai besar penduduk adalah bertani dan berkebun, sumber air untuk kebutuhan seharai hari adalah dari mata air pegunungan Penanggungan serta sumber daya listrik yang digunakan adalah pembangkit listrik tenaga mikro hidro (PLTMH) . Begitu juga dengan tradisi jawa yang masih dipertahankan di desa tersebut seperti ruwah desa, wayang kulit, seni kuda lumping dan karawitan. Sebagian besar masyarakat juga memanfaatkan bahan alam untuk pengobatan dan kebutuhan sehari hari seperti mencuci dengan biji klerek.

Kurangnya dokumentasi mengenai penggunaan tumbuhan obat oleh komunitas tertentu menyebabkan sulitnya pelestarian obat tradisional tersebut . Ditambah lagi dengan adanya modernisasi akibat masuknya kebudayaan dari luar, terutama yang diadopsi oleh generasi muda membuat makin lunturnya pengetahuan lokal pada komunitas tertentu (Indrayangingsih et al., 2015)

Salah satu pendekatan yang dapat digunakan untuk menggali pengetahuan lokal komunitas tertentu mengenai penggunaan tumbuhan sebagai obat adalah etnobotani. Melalui studi ini, dimungkinkan dilakukan penelusuran mengenai bahan-bahan obat tradisional, dan cara penggunaannya sebagai penciri budaya dalam suatu komunitas tertentu (Oktoba, 2018).. Oleh karena itu pada 
penelitian ini akan dilakukan studi etnobotani dan dan identifikasi tumbuhan obat berbasis pengetahuan lokal di Desa Seloliman Kecamatan Trawas Kabupaten Mojokerto Jawa Timur.

\section{METODE PENELITIAN}

Penelitian yang dilakukan adalah jenis penelitian deskriptif yang dilakukan di desa Seloliman Kecamatan Trawas
Kabupaten Mojokerto pada bulan November 2018. Sumber data diperoleh dengan metode observasi, bertanya secara langsung kepada dua herbalis/ dukun di desa Seloliman. Penelitian ini bekerja sama dengan Pusat Pendidikan Lingkungan Hidup (PPLH) Seloliman Kabupaten Mojokerto. Pemilihan responeden adalah herbalis yang masih mempraktikkan pengobatan tradisional di desa tersebut.

\section{Hasil Penelitian}

Berdasarkan hasil wawancara dengan dua narasumber (herbalis) di Desa Seloliman diperoleh hasil yang dapat dilihat pada tabel 1. berikut ini;

Tabel 1. Jenis tumbuhan obat dan penggunaannya dalam pengobatan tradisional di Desa Seloliman Kecamatan Trawas Kabupaten Mojokerto Jawa Timur.

\begin{tabular}{|c|c|c|c|c|c|c|c|}
\hline No & $\begin{array}{l}\text { Nama } \\
\text { lokal/ \% } \\
\text { Jawaban } \\
\text { Penggun } \\
\text { aan }\end{array}$ & $\begin{array}{l}\text { Nama } \\
\text { Ilmiah }\end{array}$ & Familia & $\begin{array}{l}\text { Bagian } \\
\text { yang } \\
\text { digunakan }\end{array}$ & kegunaan & $\begin{array}{l}\text { Cara } \\
\text { penggun } \\
\text { aan }\end{array}$ & $\begin{array}{l}\text { Status } \\
\text { tumbuha } \\
\mathrm{n}\end{array}$ \\
\hline 1 & $\begin{array}{l}\text { Andong } \\
\text { merah } \\
(100 \%)\end{array}$ & $\begin{array}{l}\text { Cordyline } \\
\text { fruticosa }\end{array}$ & $\begin{array}{l}\text { Asparaga } \\
\text { ceae }\end{array}$ & Umbi & $\begin{array}{l}\text { Wasir,diuret } \\
\text { ik,dan } \\
\text { radang } \\
\text { saluran } \\
\text { cerna }\end{array}$ & $\begin{array}{l}\text { Minum } \\
\text { air } \\
\text { rebusann } \\
\text { ya }\end{array}$ & $\begin{array}{l}\text { LC; } \\
\text { Berisiko } \\
\text { Rendah }\end{array}$ \\
\hline 2 & $\begin{array}{l}\text { Asoka } \\
(100 \%)\end{array}$ & $\begin{array}{l}\text { Saraca } \\
\text { indica L. }\end{array}$ & Saraca & Daun & $\begin{array}{l}\text { Luka } \\
\text { memar dan } \\
\text { perdarahan } \\
\text { internal }\end{array}$ & $\begin{array}{l}\text { Mengole } \\
\text { skan } \\
\text { pada } \\
\text { luka }\end{array}$ & $\begin{array}{l}\text { LC; } \\
\text { Berisiko } \\
\text { rendah }\end{array}$ \\
\hline 3 & $\begin{array}{l}\text { Awar- } \\
\text { awar } \\
(100 \%)\end{array}$ & $\begin{array}{l}\text { Ficus } \\
\text { septica } \\
\text { Burm.f }\end{array}$ & $\begin{array}{l}\text { Moracea } \\
\text { e }\end{array}$ & Daun & $\begin{array}{l}\text { Mengobati } \\
\text { radang, usus } \\
\text { buntu,pena } \\
\text { war racun }\end{array}$ & $\begin{array}{l}\text { Minum } \\
\text { air } \\
\text { rebusann } \\
\text { ya }\end{array}$ & $\begin{array}{l}\text { VU; } \\
\text { Rentan }\end{array}$ \\
\hline 4 & $\begin{array}{l}\text { Binahon } \\
\mathrm{g} \\
(100 \%)\end{array}$ & $\begin{array}{l}\text { Anredera } \\
\text { cordifolia }\end{array}$ & $\begin{array}{l}\text { Basellac } \\
\text { eae }\end{array}$ & Daun & $\begin{array}{l}\text { Mengobati } \\
\text { luka } \\
\text { berdarah, } \\
\text { mengobati } \\
\text { jerawat }\end{array}$ & $\begin{array}{l}\text { Dioleska } \\
\mathrm{n} \text { pada } \\
\text { bagian } \\
\text { yang } \\
\text { luka }\end{array}$ & $\begin{array}{l}\text { DD; } \\
\text { Informas } \\
\text { i Kurang }\end{array}$ \\
\hline 5 & $\begin{array}{l}\text { Bakung } \\
(50 \%)\end{array}$ & $\begin{array}{l}\text { Crinum } \\
\text { asiaticum } \\
\text { L. }\end{array}$ & $\begin{array}{l}\text { Amarylli } \\
\text { daceae }\end{array}$ & Akar & Sakit gigi & $\begin{array}{l}\text { Ditempel } \\
\text { kan pada } \\
\text { gigi yang } \\
\text { sakit }\end{array}$ & $\begin{array}{l}\text { LC; } \\
\text { Beresiko } \\
\text { Rendah }\end{array}$ \\
\hline
\end{tabular}




\begin{tabular}{|c|c|c|c|c|c|}
\hline $\begin{array}{l}\text { Buah } \\
\text { kepel } \\
(100 \%)\end{array}$ & $\begin{array}{l}\text { Stelechoca } \\
\text { rpus } \\
\text { burahol }\end{array}$ & $\begin{array}{l}\text { Annonac } \\
\text { eae }\end{array}$ & Buah & $\begin{array}{l}\text { Menghalusk } \\
\text { an kulit }\end{array}$ & $\begin{array}{l}\text { Dimakan } \\
\text { langsung }\end{array}$ \\
\hline $\begin{array}{l}\text { Bunga } \\
\text { kaca } \\
\text { piring } \\
(100 \%)\end{array}$ & $\begin{array}{l}\text { Gardenia } \\
\text { jasminoide } \\
\text { s J.Ellis }\end{array}$ & $\begin{array}{l}\text { Rubiacea } \\
\text { e }\end{array}$ & Bunga & $\begin{array}{l}\text { mengobati } \\
\text { batuk } \\
\text { berdarah } \\
\text { dan dapat } \\
\text { dijadikan } \\
\text { minyak } \\
\text { atsiri. }\end{array}$ & $\begin{array}{l}\text { Minum } \\
\text { air } \\
\text { rebusann } \\
\text { ya }\end{array}$ \\
\hline
\end{tabular}

8 Bunga Canna Cannace Bunga, radang hati, Minum kana indica $\mathrm{L}$. ae rimpang/a wasir, air Berisiko $(100 \%) \quad$ kar pendarahan rebusann rendah

$9 \begin{array}{lll}\text { Bunga } & \text { Clitoria } & \text { Legumin } \\ \text { telang } & \text { ternatea } \mathrm{L} & \text { osae } \\ (100 \%) & .\end{array}$

Bunga




\begin{tabular}{|c|c|c|c|c|c|c|c|}
\hline & & & & & $\begin{array}{l}\text { mencegah } \\
\text { kerusakan } \\
\text { gigi. }\end{array}$ & ya & \\
\hline 15 & $\begin{array}{l}\text { Daun } \\
\text { jarak } \\
\text { pagar } \\
(100 \%)\end{array}$ & $\begin{array}{l}\text { Jatropha } \\
\text { curcas L. }\end{array}$ & $\begin{array}{l}\text { Euphorbi } \\
\text { aceae }\end{array}$ & Daun & Rematik & $\begin{array}{l}\text { Minum } \\
\text { air } \\
\text { rebusann } \\
\text { ya }\end{array}$ & $\begin{array}{l}\text { VU; } \\
\text { Rentan }\end{array}$ \\
\hline 16 & $\begin{array}{l}\text { Daun } \\
\text { mangkok } \\
- \\
\text { mangkok } \\
\text { an } \\
(100 \%)\end{array}$ & $\begin{array}{l}\text { Polyscias } \\
\text { scopoliae }\end{array}$ & $\begin{array}{l}\text { Araliace } \\
\text { ae }\end{array}$ & Daun & $\begin{array}{l}\text { Menyuburk } \\
\text { an rambut }\end{array}$ & $\begin{array}{l}\text { Mengole } \\
\text { skan } \\
\text { pada } \\
\text { rambut }\end{array}$ & $\begin{array}{l}\text { DD; } \\
\text { Informas } \\
\text { i kurang }\end{array}$ \\
\hline 17 & $\begin{array}{l}\text { Daun } \\
\text { dandang } \\
\text { gendis } \\
(100 \%)\end{array}$ & $\begin{array}{l}\text { Clinacant } \\
\text { hus nutans }\end{array}$ & $\begin{array}{l}\text { Acanthac } \\
\text { eae }\end{array}$ & Daun & $\begin{array}{l}\text { Menurunka } \\
\text { ngula darah }\end{array}$ & $\begin{array}{l}\text { Minum } \\
\text { air } \\
\text { rebusann } \\
\text { ya }\end{array}$ & $\begin{array}{l}\text { DD; } \\
\text { Informas } \\
\text { i Kurang }\end{array}$ \\
\hline 18 & $\begin{array}{l}\text { Daun } \\
\text { encok } \\
(100 \%)\end{array}$ & $\begin{array}{l}\text { Plumbago } \\
\text { zeylanica } \\
\text { L. }\end{array}$ & $\begin{array}{l}\text { Plumbag } \\
\text { inaceae }\end{array}$ & Daun & $\begin{array}{l}\text { Rematik } \\
\text { sendi, encok }\end{array}$ & $\begin{array}{l}\text { Pemakai } \\
\text { an luar, } \\
\text { daun } \\
\text { diremas } \\
\text { lalu } \\
\text { diletakka } \\
\text { n pada } \\
\text { bagian } \\
\text { tubuh } \\
\text { yang } \\
\text { kena } \\
\text { rematik, } \\
\text { sakit } \\
\text { pinggang } \\
\text {, memar. }\end{array}$ & $\begin{array}{l}\text { DD; } \\
\text { Informas } \\
\text { i Kurang }\end{array}$ \\
\hline 19 & $\begin{array}{l}\text { Daun } \\
\text { suji } \\
(100 \%)\end{array}$ & $\begin{array}{l}\text { Dracaena } \\
\text { angustifoli } \\
a .\end{array}$ & $\begin{array}{l}\text { Asparaga } \\
\text { ceae }\end{array}$ & Daun & $\begin{array}{l}\text { mengobati } \\
\text { beri-beri, } \\
\text { penawar } \\
\text { racun, } \\
\text { menurunkan } \\
\text { kadar } \\
\text { kolesterol }\end{array}$ & $\begin{array}{l}\text { Minum } \\
\text { air } \\
\text { rebusann } \\
\text { ya }\end{array}$ & $\begin{array}{l}\text { DD; } \\
\text { Informas } \\
\text { i Kurang }\end{array}$ \\
\hline 20 & $\begin{array}{l}\text { Daun } \\
\text { salam } \\
(100 \%)\end{array}$ & $\begin{array}{l}\text { Syzygium } \\
\text { polyanthu } \\
m\end{array}$ & $\begin{array}{l}\text { Myrtacea } \\
\text { e }\end{array}$ & Daun & Asam urat & $\begin{array}{l}\text { Minum } \\
\text { air } \\
\text { rebusann } \\
\text { ya }\end{array}$ & $\begin{array}{l}\text { LC; } \\
\text { Berisiko } \\
\text { Rendah }\end{array}$ \\
\hline
\end{tabular}



21 Gandaru Justicia Acanthac Daun sa gendaruss eae (100\%) a Burm. (100\%) arundinac eae
23 Gigelia/P Kigelia Bignonia Buah ohon pinnata ceae
sosis atau
(100\%) Kigelia africana (Lam.)

$\begin{array}{lll}\text { memar, } & \text { Mengole } & \text { DD; } \\ \text { kesleo, } & \text { skan } & \text { Informas } \\ \text { rematik, } & \text { pada } & \text { i Kurang } \\ \text { tulang } & \text { bagian } & \\ \text { patah. } & \text { yang } & \\ & \text { sakit } & \end{array}$

22 Garut Maranta Marantac Pati Umbi Mengobati

Di buat DD; luka bubur Informas umbinya i Kurang yang sudah di haluskan

Dioleska LC;

24 Jarak Jatropha Euphorbi Daun kendil curcas L. aceae $(100 \%)$

$\begin{array}{lll}\text { Mengatasi } & \text { Dioleska } & \text { LC; } \\ \text { bisul } & \mathrm{n} \text { hasil } & \text { Berisiko } \\ & \text { tumbuka } & \text { Rendah } \\ & \mathrm{n} \text { pada } & \\ & \text { bisul }\end{array}$
Rematik Mengole LC;
skan Berisiko
tumbuka Rendah
n daun
pada
bagian
yang
sakit

25 Jarak Jatropha Euphorbi Daun merah gossypiifol aceae $(100 \%) \quad$ ia L.

$\begin{array}{lll}\text { Sebagai } & \text { Minum } & \text { VU; } \\ \text { pencahar } & \text { air } & \text { Rentan } \\ \text { dan demam } & \text { seduhann } & \\ & \text { ya } & \\ \text { Melangsing } & \text { Minum } & \text { LC; } \\ \text { kan tubuh } & \text { air } & \text { Berisiko } \\ & \text { rebusann } & \text { Rendah } \\ & \text { ya } & \end{array}$

27 Jinten Nigella Ranuncu Biji hitam sativa $\mathrm{L}$ laceae

Rematik, Minum LC; peningkat air Berisiko $(100 \%)$ daya tahn seduhann Rendah tubuh, ya antipiretik dan untuk batuk.

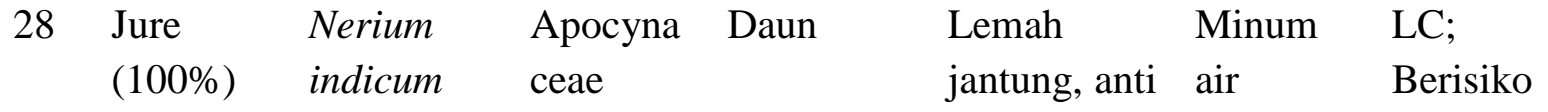


Mill. atau

Nerium

oleander

L.

29 Katu Sauropus Phyllant Daun (100\%) androgynu haceae $s(\mathrm{~L}$.

30 Kitolod Isotoma Campan Bunga (100\%) longiflora ulaceae

(L.)

C.Presl

atau

Hippobro

ma

longiflora

(L.)

G.Presl

kanker, rebusann Rendah

asma, sakit ya

gigi

Memperlan Minum LC;

car ASI, air Berisiko

bisul, luka rebusann Rendah

ya

Obat tetes Getahny DD;

mata a

Informas

diteteska i Kurang

n pada

mata

$\begin{array}{lll}\begin{array}{l}\text { menghilang } \\ \text { kan bau } \\ \text { badan, } \\ \text { pengusir }\end{array} & \begin{array}{l}\text { Makan } \\ \text { olahan } \\ \text { nyamuk dan } \\ \text { sudah }\end{array} & \begin{array}{l}\text { Lerisiko } \\ \text { direbus }\end{array} \\ \text { Rendah } \\ \text { Batu ginjal, } \\ \text { asam urat } & \text { Minum } & \text { VU; } \\ & \text { rebusann } & \text { Rentan } \\ & \text { ya } & \\ \text { Masuk } & \text { Minum } & \text { LC; } \\ \text { angin } & \text { air } & \text { Berisiko } \\ & \text { perasann } & \text { Rendah } \\ & \text { ya } & \end{array}$

Ketombe Mengole LC;

dan skan gel Beresiko

melebatkan dari daun Rendah

rambut yang

telah

dibelah

pada

rambut

35 Lidah Sansevieri Asparaga Daun

mertua

ceae

Menyerap Ditanam LC;

racun, tumbuha Berisiko

polusi udara nnya Rendah 
(50\%) Prain

36 Mahkota Phaleria Thymela Daun dan Asam urat Diminu LC; dewa macrocarp eaceae kulitbuah $\mathrm{m}$ Berisiko $(100 \%) \quad a$

ekstrak Rendah

cairan

yang

telah

diperoleh

37 Murbey Morus Moracea Daun,Bua Memperkua Buahnya LC;

$(100 \%)$ alba $\mathrm{L}$. e $\mathrm{h}$, akar, $\mathrm{t}$ ginjal, dimakan Berisiko ranting Sirkulasi langsung Rendah darah, atau

Sesak nafas, bagian

Muka lainnya

bengkak , dengan

Sakit gigi, pengolah

Sakit an

pinggang ,

Kram,

Penyubur

rambut

38 Nampu Alocasia Araceae Daun Rematik, Minum CR;

(100\%) cucculata

pegal air Kritis

linu,dan rebusann

afrodisiak ya

39 Pacing Coctus Costacea Batang, Eksim Dioleska DD;

(100\%) speciosus e rimpang (gatal-gatal) $\mathrm{n}$ bunga Informas

(J.Koenig)

yang i Kurang

Sm. atau

sudah

Cheilocost

ditumbu

us

$\mathrm{k}$

speciosus

40 Pegagan Centella Umbellif Daun Melancarka Minum LC;

$(100 \%)$ asiatica erae $\mathrm{n}$ darah air Berisiko

(L.) rebusann Rendah

ya

41 Pecut Stachytarp Verbena Seluruh Rematik, Minum VU;

kuda heta ceae bagian keputihan, air Rentan

$(100 \%)$ jamaicensi herba dan rebusann

$s$ (L.) hepatitis ya

42 Puring Codiaeum Euphorbi Daun dan Sakit perut, Minum LC;

(100\%) variegatu aceae akar sukar air Berisiko 
$m(\mathrm{~L}$.

43 Pulosari Alyxia (100\%) stellata.

$\begin{array}{ll}\text { keringat, } & \text { rebusan } \\ \text { sembelit, } & \text { dan } \\ \text { kejang } & \text { mengole } \\ \text { lambung, } & \text { skan } \\ \text { perut mulas } & \text { tumbuka } \\ & \text { n pada } \\ & \text { bagian } \\ & \text { yang } \\ & \text { sakit }\end{array}$

sariawan, Minum EN;

batuk, air Teranca

keputihan, rebusann $\mathrm{m}$

mengatasi ya

perut

kembung.

$\begin{array}{llll}\text { Portulak } & \text { Portulaca } & \text { Portulaca Daun } \\ \text { a/krokot } & \text { grandiflor } & \text { ceae } & \\ (100 \%) & \text { a Hook } & & \end{array}$

45 Rhoeo Rhoeo Commeli Daun discolor discolor naceae (50\%) (L’Her.)

46 Sambilot Andrograp Acanthac Daun $\begin{array}{lll}\text { o }(100 \%) & \text { his eae } \\ & \text { paniculata }\end{array}$

47 Secang Caesalpini Legumin Kulit (100\%) a sappan osae batang $\mathrm{L}$.

(20) 


\begin{tabular}{|c|c|c|c|c|c|c|c|}
\hline & & $\begin{array}{l}\text { um } \\
\text { pinnatum } \\
\text { (Lam.) }\end{array}$ & & & & $\begin{array}{l}\text { yang } \\
\text { telah di } \\
\text { haluskan }\end{array}$ & \\
\hline 50 & $\begin{array}{l}\text { Saga } \\
\text { telik } \\
(100 \%)\end{array}$ & $\begin{array}{l}\text { Abrus } \\
\text { precatoriu } \\
\text { s L. }\end{array}$ & $\begin{array}{l}\text { Legumin } \\
\text { osae }\end{array}$ & Daun & $\begin{array}{l}\text { Sariawan } \\
\text { dan amndel }\end{array}$ & $\begin{array}{l}\text { Berkumu } \\
\mathrm{r} \text { dengan } \\
\text { air } \\
\text { rebusann } \\
\text { ya }\end{array}$ & $\begin{array}{l}\text { DD; } \\
\text { Informas } \\
\text { i Kurang }\end{array}$ \\
\hline 51 & $\begin{array}{l}\text { Sambung } \\
\text { colok } \\
(100 \%)\end{array}$ & $\begin{array}{l}\text { Aerva } \\
\text { sanguinole } \\
\text { nta }(\mathrm{L} .)\end{array}$ & $\begin{array}{l}\text { Amarant } \\
\text { haceae }\end{array}$ & Daun & $\begin{array}{l}\text { Haid tidak } \\
\text { teratur dan } \\
\text { keputihan }\end{array}$ & $\begin{array}{l}\text { Minum } \\
\text { air } \\
\text { rebusann } \\
\text { ya }\end{array}$ & $\begin{array}{l}\text { LC; } \\
\text { Berisiko } \\
\text { rendah }\end{array}$ \\
\hline 52 & $\begin{array}{l}\text { Sambang } \\
\text { getih } \\
(100 \%)\end{array}$ & $\begin{array}{l}\text { Hemigrap } \\
\text { his } \\
\text { alternata } \\
\text { (Burm. f.) } \\
T . \\
\text { Anderson }\end{array}$ & $\begin{array}{l}\text { Acanthac } \\
\text { eae }\end{array}$ & Daun & $\begin{array}{l}\text { Disentri dan } \\
\text { wasir }\end{array}$ & $\begin{array}{l}\text { Minum } \\
\text { air } \\
\text { rebusann } \\
\text { ya }\end{array}$ & $\begin{array}{l}\text { LC; } \\
\text { Berisiko } \\
\text { Rendah }\end{array}$ \\
\hline 53 & $\begin{array}{l}\text { Tapak } \\
\text { Liman } \\
(100 \%)\end{array}$ & $\begin{array}{l}\text { Elephanto } \\
\text { pus scaber } \\
\text { L. }\end{array}$ & $\begin{array}{l}\text { Asterace } \\
\text { ae }\end{array}$ & Daun & $\begin{array}{l}\text { Diare, } \\
\text { hepatitis, } \\
\text { sakit perut, } \\
\text { demam }\end{array}$ & $\begin{array}{l}\text { Minum } \\
\text { air } \\
\text { rebusann } \\
\text { ya }\end{array}$ & $\begin{array}{l}\text { LC; } \\
\text { Beresiko } \\
\text { Rendah }\end{array}$ \\
\hline 54 & $\begin{array}{l}\text { Valerian } \\
\text { hutan } \\
(100 \%)\end{array}$ & $\begin{array}{l}\text { Valeriana } \\
\text { officinalis } \\
\text { L. }\end{array}$ & $\begin{array}{l}\text { Caprifoli } \\
\text { aceae }\end{array}$ & Akar & $\begin{array}{l}\text { Mengobati } \\
\text { syaraf }\end{array}$ & $\begin{array}{l}\text { Akar } \\
\text { dibuat } \\
\text { ekstrak } \\
\text { lalu } \\
\text { diseduh }\end{array}$ & $\begin{array}{l}\text { LC; } \\
\text { Berisiko } \\
\text { Rendah }\end{array}$ \\
\hline 55 & $\begin{array}{l}\text { Yodium } \\
(100 \%)\end{array}$ & $\begin{array}{l}\text { Jatropha } \\
\text { multifida } \\
\mathrm{L}\end{array}$ & $\begin{array}{l}\text { Euphorbi } \\
\text { aceae }\end{array}$ & Getah & $\begin{array}{l}\text { Mengobati } \\
\text { luka }\end{array}$ & $\begin{array}{l}\text { Dioleska } \\
\mathrm{n} \text { pada } \\
\text { luka }\end{array}$ & $\begin{array}{l}\text { VU; } \\
\text { Rentan }\end{array}$ \\
\hline
\end{tabular}

Tabel 2. Cara Memperoleh Tumbuhan yang Digunakan Dalam Pengobatan Tradisional Di Desa Seloliman Kecamatan Trawas Kabupaten Mojokerto Jawa Timur.

\section{No Nama Tanaman}

$1 \quad$ Kembang bakung

2 Sosor bebek

3 Bunga Sepatu

$4 \quad$ Lidah buaya

5 Rheodiscolor (nanas kerang)

\section{Cara Memperoleh}

Dari tumbuhan liar di sekitar dan ada yang sengaja ditanam

Dari tumbuhan yang sengaja ditanam

Dari tumbuhan yang sengaja ditanam

Dari tumbuhan yang sengaja ditanam

Dari tumbuhan yang sengaja ditanam 


\begin{tabular}{ll}
6 & Tapak Liman \\
7 & Sirih hutan \\
8 & Bunga terompet \\
9 & Daun ungu \\
& \\
10 & Daun jarak \\
& \\
11 & Mahkota dewa \\
12 & Lidah mertua \\
13 & Kumis kucing \\
14 & Lengkuas \\
& \\
15 & Daun Mangkok-mangkokan \\
16 & Sambiloto \\
& \\
17 & Pegagan \\
18 & Daun encok \\
& \\
19 & Dandang gendis \\
20 & Bunga soka \\
& \\
21 & Daun landep \\
22 & Jarak kendil \\
& \\
23 & Puring \\
24 & Gandarusa \\
\hline &
\end{tabular}

25 Pulosari

26 Pecut kuda

27 Daun suji

28 Jati Belanda

29 Jarak merah

30 Buah maja

31 Buah kepel

32 Sambang getih

33 Yodium
Dari tumbuhan liar

Dari tumbuhan yang sengaja ditanam

Dari tumbuhan yang sengaja ditanam

Dari tumbuhan yang sengaja ditanam dan tumbuhan liar

Dari tumbuhan yang sengaja ditanam dan tumbuhan liar

Dari tumbuhan yang sengaja ditanam

Dari tumbuhan yang sengaja ditanam

Dari tumbuhan liar

Dari tumbuhan yang sengaja ditanam dan dibeli dari pasar

Dari tumbuhan yang sengaja ditanam

Dari tumbuhan yang sengaja ditanam dan tumbuhan liar

Dari tumbuhan liar

Dapat didapat dengan mudah tumbuh secara liar di ladang, tepian saluran air , atau pekarangan.

Didapat dari tumbuhan liar di pekarangan

Dari tumbuhan yang sengaja ditanam sebagai tanaman hias

Tumbuh liar atau ditanam untuk pagar halaman

Terdapat di hutan, tanah kosong, di daerah pantai dan perkebunan

Dari tumbuhan yang sengaja ditanam

Tumbuh liar di hutan, tanggul sungai atau dipelihara sebagai tanaman pagar atau tanaman obat.

Tanaman liar yang tumbuh di dalam hutan dan kawasan pegunungan penanggungan dan bisa didapatkan dari PPLH Seloliman

Dari tumbuhan liar

Dari tumbuhan yang sengaja ditanam atau dibeli di pasar

Dibeli di pasar atau penduduk setempat bisa mendapatkannya di PPLH Seloliman

Masyarakat Seloliman biasanya mengambil sekitar rumah-rumah mereka.

Dari tumbuhan yang sengaja di tanam

Dari tumbuhan yang sengaja ditanam atau tumbuh liar, namun sekarang sudah mulai punah

Bisa ditemukan tumbuh liar atau ditanam di halaman dan taman-taman sebagai tanaman hias.

Tanaman hias yang sengaja ditanam 
34 Daun salam

35 Portulaka

36 Jinten Hitam

37 Murbey

38 Kitolod

39 Sambung colok

40 Jure

41 Daun katu

42 Bunga kana

43 Bunga telang

44 Awar-awar

45 Valerian hutan

46 Daun duduk

47 Bunga kaca piring

48 Binahong

49 Andong merah

50 Kecombrang

51 Pacing

52 Nampu

53 Saga telik

54 Garut

55 Pohon sosis

56 Secang
Tumbuh liar dan tanaman yang sengaja ditanam

Tanaman hias yang sengaja dibudidaya

Tanaman yang dibudidaya

Tanaman budidaya

Tumbuhan liar

Tumbuhan liar

Tumbuhan liar

Ditanam dihalaman rumah

Tumbuhan liar

Tumbuhan liar

Tanaman liar dihutan merupakan tumbuhan semak.

Tumbuhan liar di hutan

Tumbuhan liar

Tanaman hias yang sengaja dibudidaya

Tanaman budidaya

Tanaman hias yang dibudidaya

Tanaman yang ditanam di pekarangn rumah

Tanaman yang ditanam di pekarangn rumah

Tumbuhan liar

Tumbuhan liar

Tanaman budidaya

Tumbuhan liar dan sengaja ditanam

Dibeli dari pasar dan sengaja ditanam

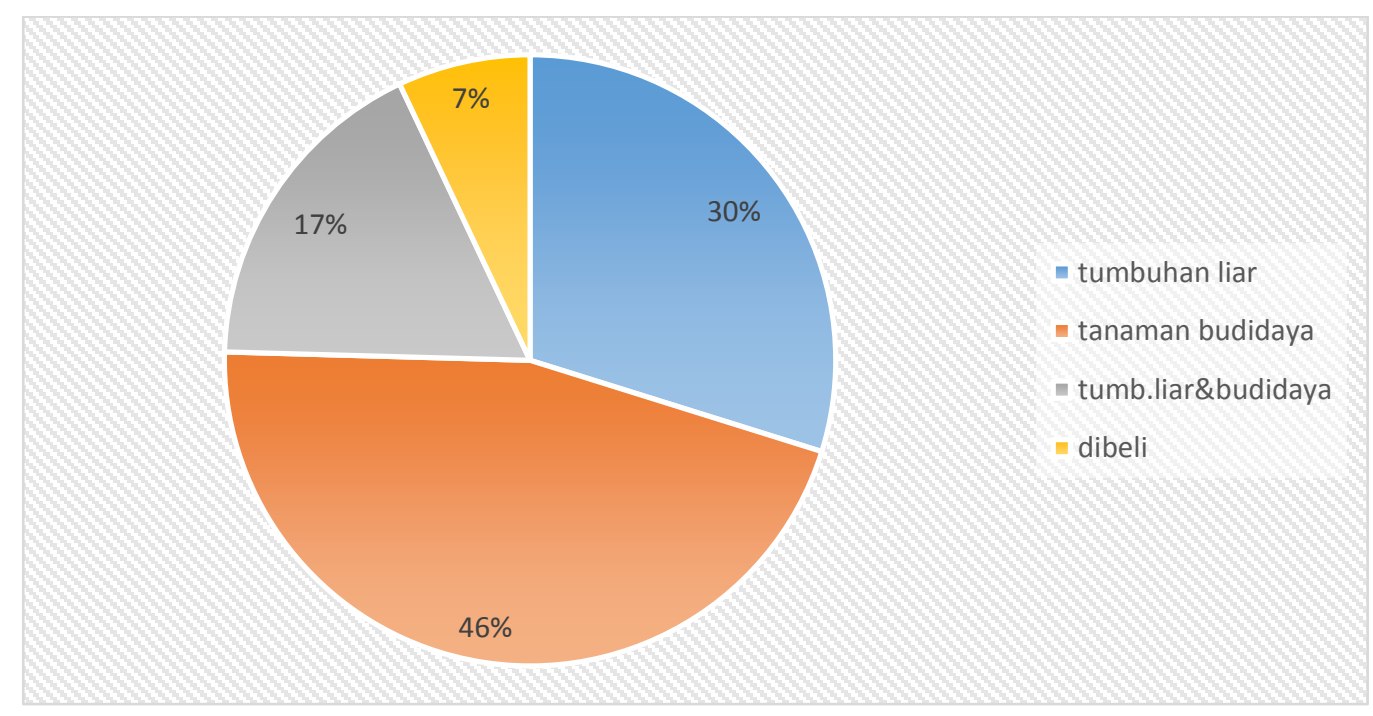

Gambar 1. Diagram Cara Memperoleh Tumbuhan yang Digunakan Dalam Pengobatan Tradisional Di Desa Seloliman Kecamatan Trawas Kabupaten Mojokerto Jawa Timur. 


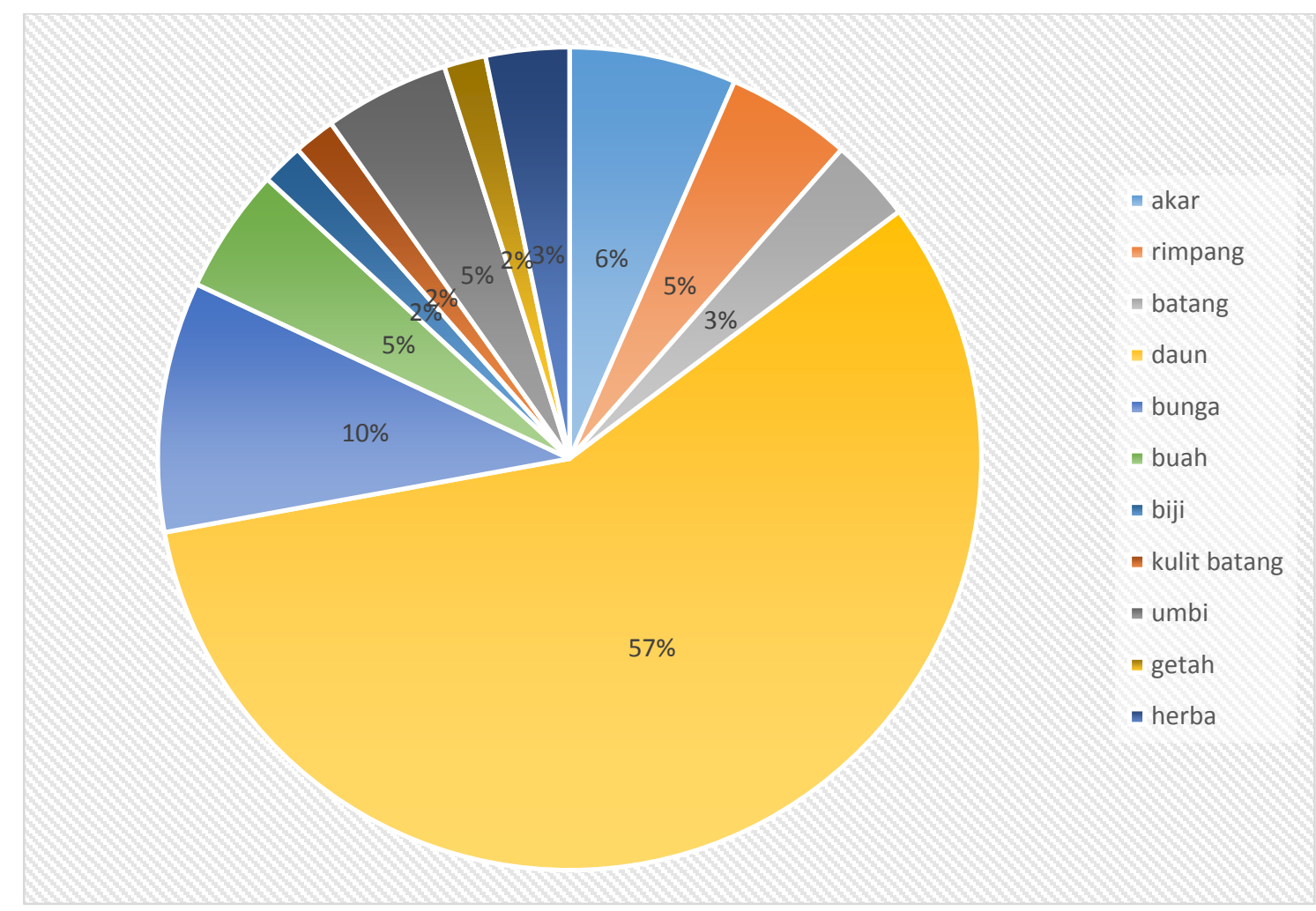

Gambar 2. Diagram Bagian Tumbuhan yang Digunakan Dalam Pengobatan Tradisional Di Desa Seloliman Kecamatan Trawas Kabupaten Mojokerto Jawa Timur.

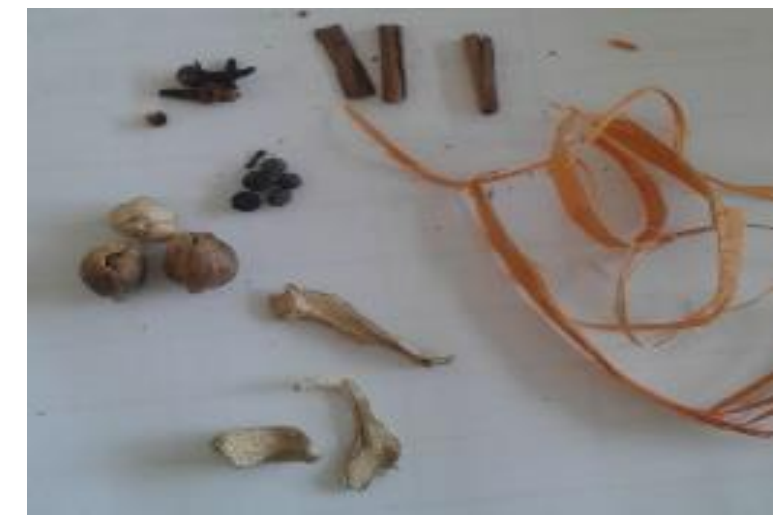

Gambar 3. Ramuan Secang di Desa Seloliman

\section{HASIL DAN PEMBAHASAN}

Dari data yang diperoleh terdapat 55 tumbuhan di Desa Seloliman yang memiliki khasiat masing-masing yang dapat digunakan dalam pengobatan tradisional. Berdasarkan data dari IUCN Red List, dari 55 tumbuhan tersebut terdapat 30 tumbuhan dengan status LC (Berisiko Rendah), 13 tumbuhan berstatus DD (informasi kurang), 7 tumbuhan berstatus VU (Rentan), 3 tumbuhan berstatus CR (Kritis), 1 tumbuhan berstatus VT (Hampir Terancam), dan 1 tumbuhan berstatus Terancam. Tumbuhan dengan 
status CR (Kritis) perlu dilakukan budidaya dan pelestarian agar tidak punah. Mengingat manfaatnya yang juga didak kalah penting digunakan dalam pengobatan tradisional. Cara memperoleh tumbuhan yang digunakan untuk pengobatan tradisional berdasarkan hasil wawancara dengan dua nara sumber dari PPLH di Desa Seloliman (Bapak Yuda dan Bapak Iswandi) diperoleh hasil yang dapat dilihat pada tabel 2 .

Jenis-jenis tumbuhan yang digunakan dalam sistem pengobatan pada umumnya tumbuh di sekitar pekarangan rumah dan dikembangkan dengan teknik sederhana (asal tanam), atau tumbuh liar di sekitar area perkebunan dan persawahan warga. Berdasarkan penampakan diagram tersebut, 46\% tumbuhan di Desa Seloliman merupakan tanaman budidaya, $30 \%$ merupakan tumbuhan liar, 17\% merupakan tumbuhan liar dan budidaya, serta $7 \%$ merupakan tumbuhan yang diperoleh dari pasar atau dari penjual tertentu.

Bagian tumbuhan yang diambil sebagai obat antara lain rimpang, batang, kulit batang, daun, bunga, buah, biji, dan kulit batang. Bagian tumbuhan yang banyak digunakan untuk pengobatan yaitu daun sebesar 57\%. Daun merupakan tempat akumulasi hasil fotosintesis yang diduga mengandung unsur-unsur zat organik yang memiliki sifat menyembuhkan penyakit. Zat yang banyak terdapat pada daun adalah minyak atsiri, fenol, senyawa kalium, dan klorofil. Klorofil telah diuji mampu menanggulangi penyakit anemia dengan baik, karena zat ini berfungsi sama seperti hemoglobin pada darah manusia (Dianto et al., 2015)

Kulit kayu secang adalah tanaman yang paling banyak digunakan dalam pengobatan tradisional di desa ini. Jumlah kayu secang atau bahan-bahan lain yang digunakan dalam tradisi suku Jawa di Desa Seloliman adalah berjumlah ganjil (tiga, lima, atau tujuh). Ramuan secang dapat dilihat pada Gambar 3.

Kayu secang (Caesalpinia sappan L.)merupakan tanaman famili Caesalpiniaceae yang banyak ditemui di Indonesia.Kayu secang secara empiris diketahui memiliki banyak khasiat penyembuhan dan sering dikonsumsi oleh masyarakat sebagai minuman kesehatan. Kayu secang memiliki kandungan senyawa berupa brazilin (C16H14O5), sappanin (C12H12O4), brazilein, dan minyak atsiri seperti D- $\alpha$-felandrena, asam galat, osinema, dan damar. Kayu secang memiliki daya antioksidan yang andal dengan indeks antioksidatif ekstrak air kayu secang lebih tinggi daripada antioksidan komersial (BHT dan BHA) sehingga potensial sebagai agen penangkal radikal bebas. Ekstrak etanolik kayu secang (EEKS) berpotensi menjadi agen kemopreventif dilihat dari hasil uji sitotoksik terhadap sel kanker payudara 4T1. (Hanif et al., 2017)

Terdapat tanaman obat yang sudah jarang ditemui yaitu kepel. Kepel merupakan buah kegemaran putri-putri keraton kerajaan Majapahit karena khasiatnya yang mampu mengharumkan bau keringat, urin dan nafas. Bentuk buah tanaman kepel menyerupai kepalan tangan yang memiliki nilai filosofi sebagai perlambang kesatuan serta keutuhan mental dan fisik.

Buah kepel sudah sangat jarang dan mulai sulit ditemukan. Tanaman kepel telah masuk dalam Daftar Tanaman Langka .Kelangkaan tanaman kepel masuk dalam kategori CR (Critis) sesuai data IUCN Red list yang artinya keberadaannya 
sulit ditemui karena telah langka (rare) dan jika tidak dilakukan tindakan konservasi maka statusnya dapat meningkat satu tahap di atasnya, yaitu rawan (vulnerable). Banyak faktor yang menyebabkan tanaman kepel menjadi langka, antara lain terbentuknya opini bahwa tanaman ini hanya boleh ditanam di sekitar keraton, sulit dibudidayakan serta memiliki nilai ekonomi yang rendah sehingga masyarakat enggan membudidaya tanaman tersebut.

Buah kepel mengandung saponin dan flavonoid, senyawa tersebut diketahui memiliki aktivitas sebagai antimikroba, antiinflamasi, antivirus dan antioksidan. Daun kepel mengandung senyawa terpenoid dan flavonoid (Purwatiningsih and Rahman Hakim, 2013) (Hidayat et al., (2011) menambahkan ekstrak dari daun kepel mengandung senyawa flavonoid meliputi auron, flavanon dan flavanol yang dapat digunakan untuk antibakteri.

\section{SIMPULAN}

Berdasarkan dari penelitian yang sudah dilakukan telah diidentifikasi terdapat 56 jenis tanaman obat yang masih digunakan untuk pengobatan tradisional. Pengolahan tanaman obat tersebut hanya direbus. Jenis tanaman yang digunakan untuk pengobatan sangat bervariasi, bagian tanaman yang digunakan sebagian besar adalah bagian daun (57\%), bunga (10\%), dan sisanya adalah bagian batang, kulit batang, rimpang, akar, bunga, buah, dan biji. Sumber tanaman yang digunakan sebagian besar adalah tanaman budidaya (46\%), liar (30\%), liar dan budidaya (17\%) dan membeli di pasar (7\%). Sebagian besar Masyarakat desa Seloliman Kecamatan Trawas Kabupaten Mojokerto Jawa Timur sudah terpengaruh oleh budaya luar, sehingga pengetahuan lokalnya mengenai tumbuhan yang digunakan dalam pengobatan perlu digali lebih jauh agar dapat dilestarikan. Hanya terdapat terdapat dua narasumber (pengobat tradisional) di desa Seloliman yang masih memegang tradisi terkait pengobatan dengan menggunakan bahan alam.

\section{UCAPAN TERIMAKASIH}

Terimakasih kepada Pusat Pendidikan Lingkungan Hidup (PPLH) Seloliman Trawas Kabupaten Mojokerto dan kedua narasumber yaitu bapak Yuda dan bapak Iswandi.

\section{DAFTAR PUSTAKA}

Balai Besar Penelitian Dipterokarpa, Karmilasanti, K., Supartini, S., Balai Besar Penelitian Dipterokarpa, 2011. Keanekaragaman Jenis Tumbuhan Obat Dan Pemanfaatannya Di Kawasan Tane' Olen Desa Setulang Malinau, Kalimantan Timur. J. Penelit. Dipterokarpa 5, 23-38.

https://doi.org/10.20886/jped.2011. 5.1.23-38

Dianto, I., Anam, S., Khumaidi, A., 2015. Studi Etnofarmasi Tumbuhan Berkhasiat Obat Pada Suku Kaili Ledo Di Kabupaten Sigi, Provinsi Sulawesi Tengah. J. Farm. Galen. Galen. J. Pharm. E-J. 1, 85-91. https://doi.org/10.22487/j24428744 .2015.v1.i2.6237

Diba, F., Tavita, G.E., 2017. Pemanfaatan Tumbuhan Obat Oleh Masyarakat Di Desa Entogong Kecamatan Kayan Hulu Kabupaten Sintang 5, 12. 
Hanif, N., Dina, A., Esti, Y.F., Taufik, M.A., Susidarti, R.A., 2017. Menunjukkan Efek Sitotoksik Pada Sel Kanker Payudara 4t1 Tetapi Tidak Melalui Jalur Reactive Oxygen Species (Ros) 10, 8.

Hidayat, A., LK, D., I, B., 2011. Fractination of the active compound from kepel (Stelechocarpus burahol) leaf extract as antibacterial. The 2nd International Symposium on Temulawak. Pusat Studi Biofarmaka LPPM IPB, IPB Bogor.

Husain, N.A., 2015. Program Studi Agroteknologi Jurusan Budidaya Pertanian Fakultas Pertanian Universitas Hasanuddin Makassar 201583.

Indrayangingsih, W.O.I., Ibrahim, N., Anam, S., 2015. Studi Etnofarmasi Tumbuhan Berkhasiat Obat Pada Suku Buton Di Kecamatan Binongko, Kabupaten Wakatobi, Sulawesi Tenggara. J. Farm. Galen. Galen. J. Pharm. E-J. 1, 79-84. https://doi.org/10.22487/j24428744 .2015.v1.i2.6236

Islami, M.Y., Ibrahim, N., Nugrahani, A.W., 2017. Studi Etnofarmasi Suku Kaili Moma Di Kecamatan Kulawi, Kabupaten Sigi, Provinsi Sulawesi Tengah: Ethnomedicinal
Study of Kaili Moma Tribe In Kulawi Subdistrict, Sigi Regency, Central Sulawesi. J. Farm. Galen. Galen. J. Pharm. E-J. 3, 27-33. https://doi.org/10.22487/j24428744 .2017.v3.i1.8136

Nugroho, I.A., 2010. Lokakarya Nasional Tumbuhan Obat Indonesia. Apforgen News Lett.

Nurrani, L., 2013. Pemanfaatan Tradisional Tumbuhan Alam Berkhasiat Obat Oleh Masyarakat Di Sekitar Cagar Alam Tangale 3, 22.

Nursiyah, 2013. Studi Deskriptif Tanaman Obat Tradisional Yang Digunakan Orangtua Untuk Kesehatan Anak Usia Dini Di Gugus Melati Kecamatan Kalikajar Kabupaten Wonosobo. Universitas Negeri Semarang, Semarang.

Oktoba, Z., 2018. Studi Etnofarmasi Tanaman Obat Untuk Perawatan Dan Penumbuh Rambut Pada Beberapa Daerah Di Indonesia. J. Jamu Indones. 3, 81-88. https://doi.org/10.29244/jji.v3i3.65

Purwatiningsih, Rahman Hakim, A., 2013. Efek Hipourikemia Ekstrak Daun Kepel [(Stelechocarpus burahol (BI).) Hook.F.\& Th] Terhadap Allopurinol Secara In Vivo 6. 